\title{
Molecular and structural bases for postsynaptic signal processing: interaction between postsynaptic density and postsynaptic membrane rafts
}

This article was published in the following Dove Press journal:

Journal of Neurorestoratology

6 December 2013

Number of times this article has been viewed

\author{
Tatsuo Suzuki' \\ Wei-Dong Yao ${ }^{2}$ \\ 'Department of Neuroplasticity, \\ Shinshu University Graduate School \\ of Medicine, Matsumoto, Japan; \\ ${ }^{2}$ Department of Psychiatry, Beth \\ Israel Deaconess Medical Center, \\ and Division of Neuroscience, \\ New England Primate Research \\ Center, Harvard Medical School, \\ Southborough, MA, USA
}

\begin{abstract}
Postsynaptic membrane rafts (or lipid rafts) (PSRs), together with the postsynaptic density (PSD), are believed to be major sites important for postsynaptic signaling, function, and plasticity. Although the PSD has received much attention and is extensively investigated, PSR roles and their relationship with PSDs are poorly understood. Our recent work has identified PSD-PSR complexes from synaptic membranes of the rat brain and demonstrated specific interactions between them in vitro. Here, we review recent progress in this field, focusing on the molecular identities of the PSR, its biochemical purification, and its potential roles in postsynaptic signaling, function, and plasticity via cross talk with the PSD. We propose that the PSR and PSD are two major postsynaptic signaling domains that interact physiologically, and that PSRs are indispensable to PSD functions. Roles of PSRs in synaptogenesis, growth, and maturation of developing PSDs, and support and regulation of functions and plasticity of mature PSDs are discussed.
\end{abstract}

Keywords: postsynaptic density, postsynaptic membrane raft, synaptic plasticity, synaptogenesis, synaptic structure

\section{Introduction}

Two major signaling apparatuses at postsynaptic sites are the postsynaptic density (PSD) and postsynaptic membrane rafts (PSRs). PSD is a well-known structure localized immediately underneath the postsynaptic membrane and a major protein network regulating postsynaptic signaling, function, and plasticity. On the contrary, the concept of lipid rafts is relatively new, and was first proposed in $1997 .{ }^{1}$ The term "membrane rafts" instead of "lipid rafts" was recommended later. ${ }^{2}$ Membrane raft domains at synaptic sites have not been well characterized, despite their potential importance at the synapse. Evidence from studies of membrane rafts in both neuronal and nonneuronal cells and subcellular regions other than synapses suggest that PSRs are important for various postsynaptic functions. Here, we review recent findings on PSRs, in particular the interaction and relationship between PSDs and PSRs, and discuss possible functional roles of PSRs.

\section{Molecular and structural bases for PSDs}

Here we provide a brief summary of basic properties and aspects of PSDs in the mammalian brain. For in-depth descriptions of the structure and function of the PSD, the readers are referred to several excellent review articles elsewhere. ${ }^{3-5}$ PSDs are electron-dense subcellular structures localizing just underneath the postsynaptic 
membrane specifically developed in the nervous system. Junctional structures between neuronal synapses were observed by electron microscopy in the 1950s, and the term "postsynaptic thickening" in asymmetric synapses was first used by Palay in $1958 .{ }^{6}$ The structure was also called postsynaptic web or postsynaptic density. ${ }^{3}$ Based on its function and properties, the PSD has also been described as the general organizer of the postsynaptic signal-transduction machinery, ${ }^{3}$ the membrane-associated protein complex (or organelle) specialized for postsynaptic signaling and plasticity, ${ }^{4}$ and signal-processing machines, ${ }^{7}$ among others. ${ }^{5,8}$ It is now clear that the PSD is not just a signal-processing machinery that mediates synaptic transmission but is also a "synaptic plasticity generator" that can change its own properties to affect efficacies of synaptic transmission. More specifically, PSD is not a static cytoskeleton but a dynamic structure, changing its properties (size, shape, composition, etc) depending on synaptic inputs.

PSDs, along with other synaptic structures, such as synaptosomes and synaptic plasma membranes (SPMs), can be biochemically purified by subcellular fractionation. Detailed methodology and procedures have been described previously. ${ }^{9}$ Components of the PSD, in particular those of excitatory type I synapses, were comprehensively identified using proteomics techniques by a number of groups. ${ }^{10-15}$ PSD proteins were also identified from the analysis of messenger RNAs associated with purified PSDs. ${ }^{16}$ PSDs associated with typical type I synapses are disk-like structures with a diameter of about $400 \mathrm{~nm}$ and thickness of $60 \mathrm{~nm}$. The molecular weight of a single PSD is calculated to be approximately $1 \mathrm{GDa}\left(\mathrm{eg}, \sim 10,000\right.$ molecules $\times 100 \mathrm{kDa}$ protein). ${ }^{4,17} \mathrm{~A}$ PSD contains several hundreds to a thousand proteins that can be classified into a wide range of functional categories. More than half of these PSD proteins have not yet been investigated, ${ }^{16}$ although a number of major PSD proteins have been intensively characterized. It is calculated that ten to several hundred molecules of individual PSD protein species are contained in a single average-sized PSD. For example, about 20 molecules of A-kinase anchoring protein 79/159 (AKAP79/150), 20 molecules of metabotropic glutamate receptor (mGluR), 60 molecules of GluA1/2/3, 60 molecules of Homer1/2/3, 150 molecules of Shank1/2/3, 150 molecules of SAP-90-PSD-95-associated protein (SAPAP) 1-4/guanylate kinase-associated protein (GKAP), 300 molecules of PSD-95, 360 molecules of synaptic guanosine triphosphatase activation protein (synGAP), and 5,600 molecules of $\mathrm{Ca}^{2+}$ calmodulin-dependent protein kinase $\operatorname{II} \alpha / \beta(\mathrm{CaMKII} \alpha / \beta)$ can be found in a PSD. ${ }^{4}$ The number of CaMKII molecules contained in a single synapse varies depending on in vivo brain conditions as well as on when the brains are dissected. ${ }^{18-20}$

Proteins in the PSD are classified into two groups based on their functions: those that assemble the cytoskeletal base of the PSD, such as scaffolding/adaptor proteins, cell adhesion proteins, and cytoskeletal proteins, and those that are attached to the PSD cytoskeletal base, such as channels, receptors, and proteins involved in the various cellular signaling cascades, metabolism, and membrane trafficking. Models of molecular architecture of PSD cytoskeletal bases have been proposed. ${ }^{5,21-24}$ Combining the concepts of these models, the PSD cytoskeletal base makes the PSD95-GKAP-Shank protein web (two-layer networks), which consists of PSD-95 extending perpendicularly from SPM to the cytoplasm with its N-terminus attached to the SPM, the ProSAP/Shank platform (PSP) localizing deep in cytoplasm, and GKAP connecting the PSD-95 layer and the PSP (Figure 1). The model proposed by Chang's group is unique in that microtubules and CaMKII are also incorporated into

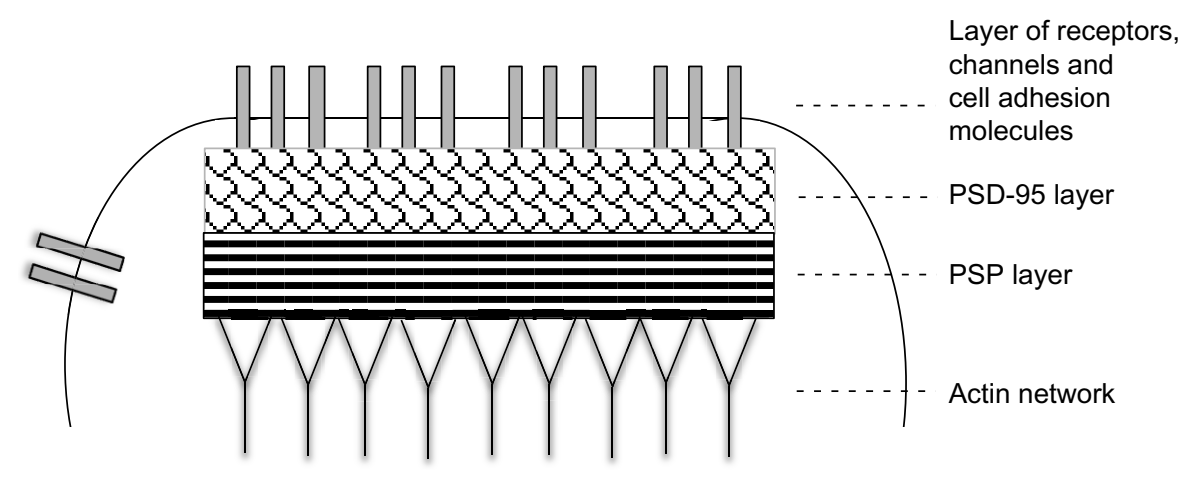

Figure I Simplified model of type I PSD cytoskeletal base. Concept of core structure of type I PSD is drawn. PSD cytoskeletal base consists of a PSD-95 layer (or PSD-95GKAP-Shank protein web) and a PSP layer. See text for details. Figure is not to scale. In particular, the PSD depth is expanded. Cytoskeletal networks mainly composed of F-actin are connected to certain points of the cytoplasmic surface of the PSD. ${ }^{126}$

Abbreviations: GKAP, guanylate kinase-associated protein; PSD, postsynaptic density; PSP, ProSAP/Shank platform. 
the core regions of PSD cytoskeletal bases. ${ }^{23,24}$ PSD proteins other than the core-forming ones are supposed to be positioned to appropriate sites of the PSD cytoskeletal bases for compartmentalization and efficiency of cellular signaling processes. PSRs have not been included in current models of postsynaptic structures, and will certainly need to be added in the future.

\section{Identification of PSD-PSR complexes}

Membrane rafts are specialized membrane domains highly enriched with cholesterol and sphingolipids, thought to compartmentalize cellular processes. They are heterogeneous in composition and size. Under static unstimulated conditions, these domains are generally small (in the order of $10 \mathrm{~nm}$ or less), but under stimulated conditions they make dynamic changes. Upon certain stimulation, small rafts can be stabilized to form larger platforms. This change is reversible. It is believed that these platforms can facilitate signal transduction and provide sites for vesicular trafficking and fusion, anchors for cytoskeletons, and support functions of transmembrane proteins, such as channels, receptors, and cell adhesion molecules. Raft domains are purified as detergent-insoluble membranes (DRMs) at low temperatures as aggregated states. DRMs are not the same as the rafts in vivo, but are useful resources for biochemical analysis, in particular for investigation of the molecular components of membrane rafts.

The relationship between PSDs and PSRs has been a point that requires clarification, because both structures are insoluble to nonionic detergents at low temperatures. Soon after the lipid raft concept was proposed, we identified one type of PSR (dendritic rafts) on the upper portion (ie, the 0.32/1.0 M sucrose interface versus PSD at the 1.5/2.1 M sucrose interface) of the sucrose gradient used for PSD purification, ${ }^{25,26}$ and found numerous PSD proteins in this fraction. Later, we purified PSRs from SPMs using a different protocol, which is more authentic to general DRM-purification protocols,,${ }^{9,27}$ and determined protein components of SPMDRMs (SPM-derived DRMs) by proteomics and compared them with those identified in the SPM-derived PSD. ${ }^{28}$ Both SPM-DRMs and PSDs are composed of functionally diverse classes of proteins. The large heterogeneity of protein categories found in the SPM-DRM and PSD fractions supports the view that PSRs and PSDs are involved in diverse functions at postsynaptic sites. In contrast, a substantial portion of proteins, in particular typical raft-associated proteins, multiple cell adhesion molecules, channels/transporters, and
G-protein/small G-protein, reside preferentially in PSRs, suggesting specific roles of PSRs compared with those of PSDs. Furthermore, many proteins are distributed in both PSDs and PSRs, suggesting a large protein overlap among the two postsynaptic structures. This heavy overlap was found to be due, at least in part, to the presence of PSD-raft complexes in the SPM-DRM.

Figure 2 summarizes the solubilization process of SPMs with Triton X (TX)-100. We should note that the yield and composition of proteins and PSD structures contained in SPM-DRMs are highly dependent on specific detergents used as well as the concentration of the detergent and detergent: protein ratio. DRM was effectively isolated after treatment with $0.05 \%-0.5 \%$ of TX-100, and was disrupted at $1.0 \%$ and higher concentrations, as judged from $\mathrm{G}_{\mathrm{M} 1}$ ganglioside distribution (Figure 2A). We selected SPM-DRMs obtained after treatment with $0.15 \% \mathrm{TX}-100$ for electron microscopy examination, because we expected from the $\mathrm{G}_{\mathrm{M} 1}$ gangliosidedistribution profile on the sucrose density gradient that raft domains and associated structures were minimally damaged by the low concentration of TX-100. Thus, we were able to identify PSD-PSR complexes with morphologically intact PSDs in the SPM-DRM. Under our condition, 0.15\% TX-100 concentration makes detergent: protein ratio of 5.6:1, and is equivalent, for example, to the system using $3.3 \mathrm{mg} / \mathrm{mL}$ of SPM proteins and 1\% TX-100 (the same detergent: protein ratio). Thus, the concentration of TX-100 for preparing DRMs is not too low compared with widely used conditions $(1.0 \%$ TX-100). We could not detect PSD-PSR complexes with morphologically intact PSDs in the previous "dendritic raft" fraction, ${ }^{26}$ possibly due to destruction by higher concentration of TX-100 (0.5\%) and higher detergent: protein ratio (8.9:1), which is equivalent to $3.0 \% \mathrm{TX}-100$ in our recent system.

Identification of PSD-PSR complexes is possible also due to the unique properties of TX-100, which is weak in disrupting raft-cytoskeleton interactions. ${ }^{29-31}$ On the contrary, $\beta$-octyl-D-glucoside (OG) completely disassociates PSD structures from PSRs and leaves DRMs with only a few raftrelated proteins. This complete separation observed in OG treatment may be explained by the presence, at the margin of each raft domain, of a lipid environment that is sensitive to $\mathrm{OG}$ extraction, as suggested by the lipid-shell hypothesis. ${ }^{32,33}$

The isolation of PSD-PSR complexes in our study was expected, because PSRs are relatively stably connected to PSDs and may provide attachment sites for PSD cytoskeletons/scaffolds. The close association between PSDs and PSRs is supported by reports showing localization of typical raft proteins, such as caveolin-1, ${ }^{34}$ striatin, ${ }^{35,36}$ zinedin,,${ }^{37}$ paralemmin,,${ }^{38}$ and 


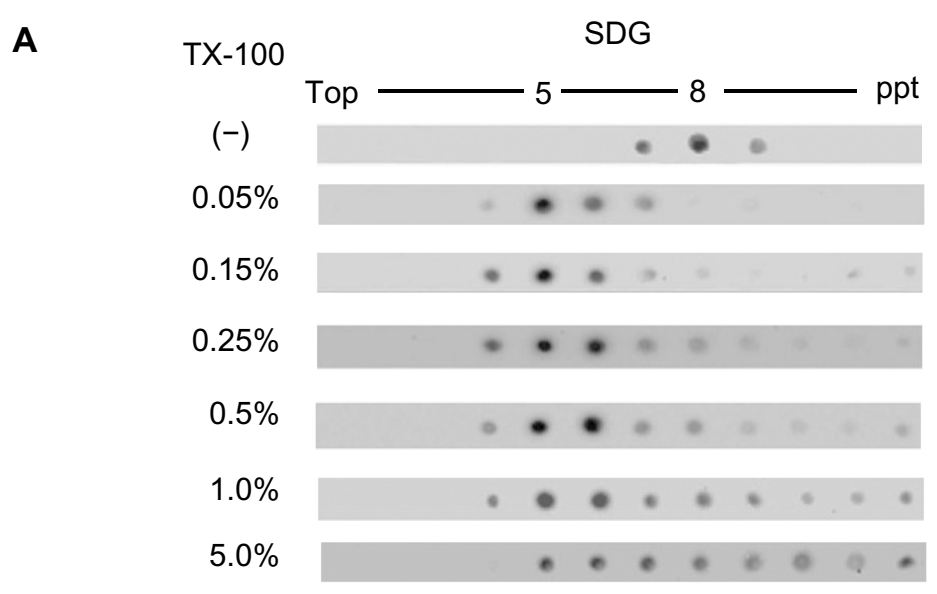

B

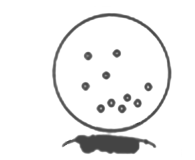

Synaptosome

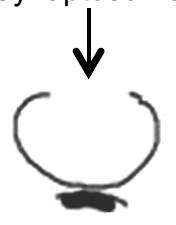

SPM

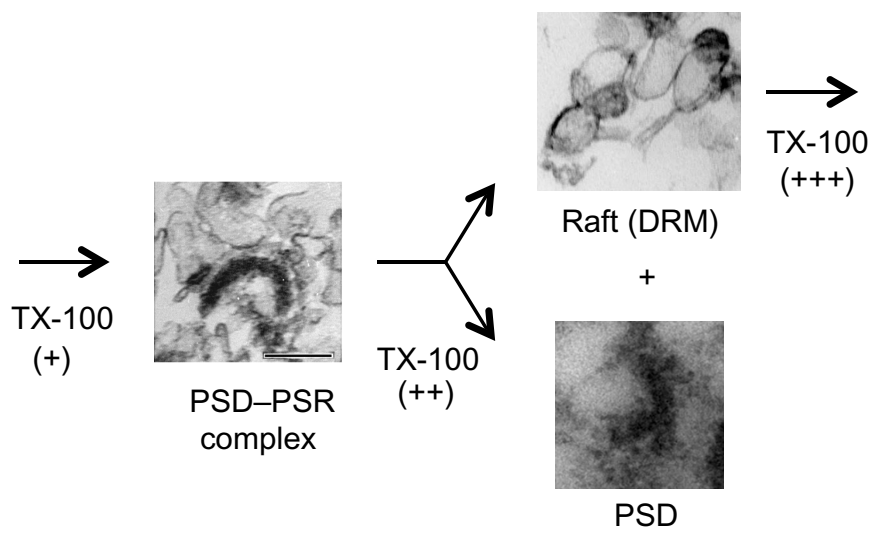

TX-100 concentration

Figure 2 (A and B) Process of TX-100 solubilization of SPMs. (A) Distribution of $G_{M I}$ ganglioside on the sucrose gradient after treatment with various concentrations of TX-100. Each fraction was dot-blotted with cholera toxin B subunit-horseradish peroxidase. (B) TX-100 spares PSD-PSR complexes at an appropriate low concentration, but disrupts the complexes and dissolves DRMs at high concentrations.

Note: Copyright (C) 2013, Dove Medical Press. Reproduced with permission from Liu Q, Yao WD, Suzuki T. Specific interaction of postsynaptic densities with membrane rafts isolated from synaptic plasma membranes. J Neurogenet. 2013;27:43-58. ${ }^{30}$

Abbreviations: SDG, sucrose density gradient; PPt, pellet; PSD, postsynaptic density; PSR, postsynaptic membrane raft; SPM, synaptic plasma membrane; DRM, detergentresistant membrane.

NAP-22, ${ }^{39}$ at or near the PSDs in the rat brains at the electron microscopic level. These typical raft proteins are localized to type I asymmetric PSDs, except for paralemmin in cerebellar PSDs. Our study ${ }^{28}$ also confirmed the complex formation between PSRs and type I PSDs in SPM-DRMs.

Colocalization of membrane rafts with synapses has also been reported in type II inhibitory PSDs ${ }^{40}$ (Suzuki, unpublished observation). Accumulating evidence demonstrates that various types of neurotransmitter receptors other than the Glu receptor, $\gamma$-aminobutyric acid A $\left(\mathrm{GABA}_{\mathrm{A}}\right)$ receptor, and glycine receptor are also codistributed with membrane rafts. ${ }^{41}$ Raft-associated neurotransmitter receptors include the $\mathrm{GABA}_{\mathrm{B}}$ receptor (metabotropic), ${ }^{42}$ nicotinic acetylcholine receptor (nAChR) ${ }^{43}$ metabotropic $\mathrm{AChR},{ }^{44}$ dopamine $\mathrm{D}_{1}$ receptor, ${ }^{45}$ and serotonin receptors $\left(5-\mathrm{HT}_{1-7}\right)$, as well as 5 -HT transporters ${ }^{46}$ and purinergic receptors, both ionotropic P2X and metabotropic P2Y. ${ }^{46}$ Additional evidence that supports raft association of non-type I synapses includes palmitoylation of $\mathrm{GABA}_{\mathrm{A}}$ receptors ${ }^{47}$ effects of cholesterol depletion on $\mathrm{GABA}_{\mathrm{A}}$ receptor $\beta 2 / 3$ subunit cluster distribution, ${ }^{48}$ and the presence and roles of membrane rafts at neuromuscular junctions. ${ }^{49}$ Membrane raft 
association of $\mathrm{nAChR}$ in somatic spines of ciliary neurons is also suggested. ${ }^{43}$ Thus, raft association is common for most, if not all, synapse types.

\section{Potential mechanisms underlying PSD-PSR interactions}

PSD-raft interaction was confirmed by an in vitro binding assay, as summarized in Figure 3. The PSD has shifted from the original heavier pellet fraction to lighter fractions on the sucrose density gradient after binding to SPM-DRMs. Purified PSDs appear to bind specifically with purified SPMDRMs, because the PSDs do not bind with SPM and show significantly lower level of binding to DRMs derived from liver membranes..$^{30}$ This suggests the presence of specific binding molecules and mechanisms for interactions between PSDs and PSRs, although details are currently unknown. There are several ways for proteins to target raft domains in the plasma membrane through protein-protein and proteinlipid interactions. These include: 1) interactions with carboxyl chains of glycosylphosphatidylinositol (GPI)-anchored proteins, 2) membrane associations of transmembrane proteins, 3) binding to cholesterol, ${ }^{32}$ and 4) membrane attachment via protein acylation, such as myristoylation and palmitoylation. ${ }^{50,51}$ PSD proteins are targets of protein palmitoylation, ${ }^{50}$ a reversible protein modification that facilitates targeting of individual PSD proteins to PSRs. ${ }^{52,53}$ Proteins can also target membrane rafts indirectly by interacting with raft-localizing proteins and lipids. For example, many proteins containing specific domains such as Pleckstrin homology $(\mathrm{PH})$, epsin N-terminal homology (ENTH) and N-terminal 4.1-ezrinradixin-moesin (FERM), bind phosphatidylinositol 4,5-bisphosphate $\left(\mathrm{PIP}_{2}\right)$ that is targeted to membrane rafts. ${ }^{54,55} \mathrm{PSD}$ is a large protein complex consisting of at least several hundred proteins, some of which can directly target membrane raft domains (Figure 4). CaMKII free from PSD is also associated with membrane rafts, ${ }^{27,56}$ but the mechanism is unknown. Thus, a single PSD appears to possess multiple means and sites for interaction with membrane rafts, which should promote PSDPSR associations.

Distribution patterns of PSD proteins, such as neurotransmitter receptors, between PSRs and PSDs when prepared as TX-100-insolubule materials have been reported to change following global ischemia ${ }^{57}$ and spatial memory formation. ${ }^{58}$ This could be due to translocation of individual PSD proteins between the two subdomains mediated by one or more mechanisms outlined earlier. However, the apparent redistribution may, at least in part, be due to differences in the extent of dissociation of PSD-PSR complexes with TX-100, as suggested in Figure 2. Mechanisms for translocation of PSD proteins between PSDs and PSRs are an important area for future investigation.

\section{PSRs in function and plasticity of mature synapses}

Accumulating evidence supports the view that PSRs are key structural components of the synapse and play indispensable

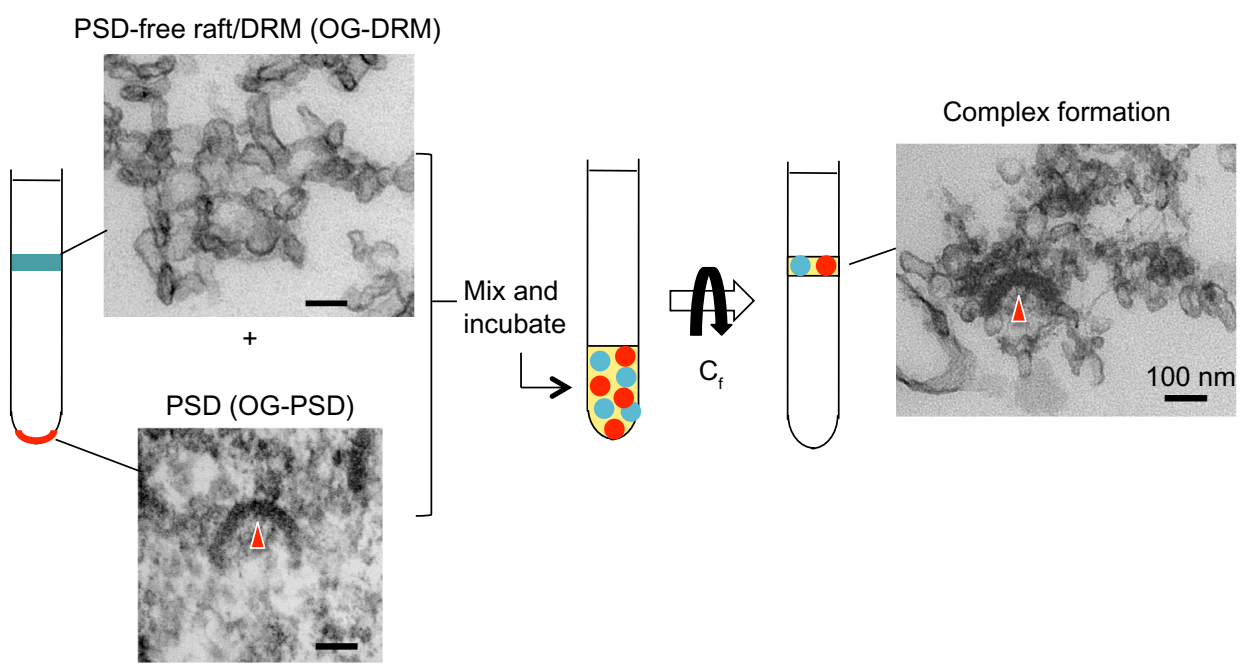

Figure 3 Summary of PSD-PSR association in vitro. Purified PSDs and PSRs were incubated at $4^{\circ} \mathrm{C}$ for 4 hours and subjected to SDG centrifugation. The floating fraction contained PSD proteins and PSD structures. PSD structures would have stayed at the pellet if not associated with DRM, suggesting PSD-PSR complexes were reconstituted in vitro. Biochemical analysis indicated that the association is specific. OG-DRM and OG-PSD refer to DRM and PSD, respectively, prepared with OG.

Note: Copyright (c) 2013, Dove Medical Press. Reproduced with permission from Liu Q, Yao WD, Suzuki T. Specific interaction of postsynaptic densities with membrane rafts isolated from synaptic plasma membranes. J Neurogenet. 2013;27:43-58. ${ }^{30}$

Abbreviations: PSD, postsynaptic density; PSR, postsynaptic membrane raft; SPM, synaptic plasma membrane; SDG, sucrose density gradient; OG, $\beta$-octyl-D-glucoside; DRM, detergent-resistant membrane. 


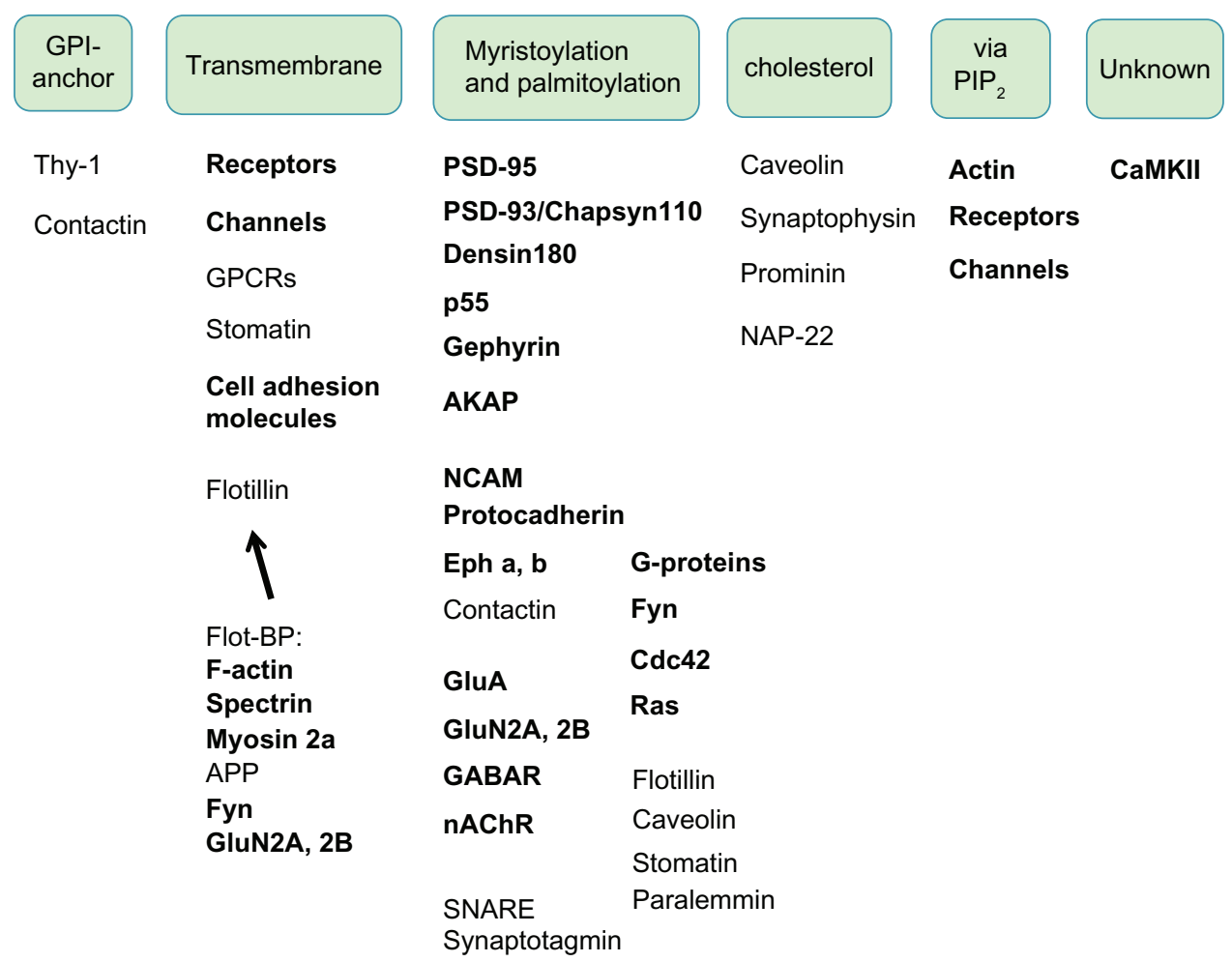

Figure 4 Possible mechanisms for PSD-PSR interactions. Mechanisms and sites for PSD-PSR interactions are likely multiple. Many PSD proteins (bold) interact directly or indirectly with PSRs as transmembrane proteins, by their acylation or via $\mathrm{PIP}_{2}$.

Abbreviations: PSD, postsynaptic density; PSR, postsynaptic membrane raft; GPI, glycosylphosphatidylinositol; PIP, phosphatidylinositol 4,5-bisphosphate; GPCRs, G-protein-coupled receptors; AKAP, A-kinase anchoring protein; CaMK, calmodulin-dependent protein kinase; NCAM, neural cell adhesion molecule; APP, Amyloid $\beta$-protein precursor; Eph, ephrin; Glu, glutamate; GABAR, $\gamma$-aminobutyric acid receptor; $\mathrm{nAchR}$, nicotinic acetylcholine receptor; SNARE, soluble $N$-ethylmaleimide-sensitive factor attachment-protein receptor.

roles in synaptic function and plasticity. Cholesterol and sphingomyelin, two essential components of membrane rafts, are abundant in the brain and synapses, and affect synaptic development, maintenance, and plasticity. ${ }^{48,59-64}$ Presynaptic roles of membrane rafts are evident by the presence of proteins deeply linked to neurotransmitter-release mechanisms (soluble $\mathrm{N}$-ethylmaleimide-sensitive factor attachment protein-receptor (SNARE) proteins, neuronal $\mathrm{Ca}^{2+}$ sensor 1 (NCS-1), and voltage-dependent $\mathrm{Ca}^{2+}$ channel $\mathrm{Ca}_{\mathrm{v}} 2.1$ ) in the DRM, and by the impairment of synaptic release associated with decreased cholesterol level. ${ }^{46}$ Ganglioside, a main constituent of membrane rafts, is also enriched in the brain ${ }^{65}$ and plays a major role in cell-cell recognition and cell signaling. ${ }^{66,67}$ Ganglioside is involved in the maintenance of neural function and plasticity, such as membrane raft-dependent neuritogenesis in Neuro-2a cells. ${ }^{68}$

Because membrane rafts at nonsynaptic sites play diverse roles in cell adhesion, cytoskeletal dynamics, cell signaling, and vesicular trafficking, ${ }^{1,28,41,69,70}$ it is expected that PSRs also play multiple roles at the synapse. In mature synapses, PSDs and PSRs may act together in maintaining PSD/spine structures and supporting dynamic changes of PSD/spine morphology. PSRs can supply membrane anchor sites for cytoskeletons/PSDs and cell adhesion molecules, and can provide signaling platforms to which various signaling molecules are recruited upon extracellular stimuli. PSRs may also provide sites for membrane fusion and vesicular trafficking ${ }^{41,70}$ which are necessary for synaptic delivery and endocytosis of surface-expressed receptors. ${ }^{71}$ Indeed, membrane rafts at synapses regulate endocytosis, exocytosis, and vesicular trafficking, ${ }^{41,70}$ including cell-surface expression of $\alpha$-amino-3-hydroxy-5-methyl-4-isoxazolepropionic acid (AMPA) receptors. ${ }^{72}$ Raft accumulation and trafficking influence the dynamics of synaptic components in and out of the synapse. ${ }^{71}$ Synapses in cultured neurons accumulate raft markers, and raft disruption leads to loss of synapses in vitro. ${ }^{48}$ Cholesterol depletion hinders cell-surface delivery of nAChR in Chinese hamster ovary (CHO) K1/A5 cells heterologously expressing mouse nAChRs, suggesting that membrane rafts participate in the trafficking and synaptic delivery of neurotransmitter receptors. ${ }^{73}$

Our proteomic analyses reveal that certain protein categories are preferentially represented in the SPM-DRM. Such groups include typical raft-associated proteins, 
various cell adhesion molecules, channels/transporters, and G-protein/small G-protein. ${ }^{28}$ The first group includes the stomatin/prohibitin/flotillin/HflK/C (SPFH) domain family (flotillin, striatin, zinedin, prohibitin, SPFH2/erlin2), paralemmin, NAP-22, and GAP43. Information on these SPM-DRM-biased proteins can offer clues to the functions of PSRs. Flotillin-1, a resident protein in noncaveolar rafts, ${ }^{25}$ is localized to excitatory synapses, and its overexpression enhances formation of glutamatergic synapses in hippocampal neurons. ${ }^{74}$ Flotillin-1 induces filopodia formation ${ }^{74}$ and promotes hippocampal neuronal differentiation. ${ }^{75}$ Flotillin induces growth cone formation and neurite outgrowth via an interaction with prion protein. ${ }^{76}$ Striatin resides in membrane rafts ${ }^{77}$ and associates with caveolin, and plays a role in endocytosis and cellular signaling. Striatin-deficient neurons display atrophic dendrites in vitro, and the transient and specific downregulation of striatin in rat striata is accompanied by a decrease in locomotor activity. ${ }^{78}$ Striatin and its partner, phocein, ${ }^{79}$ are likely to have important functions in dendritic remodeling and postsynaptic plasticity. ${ }^{80}$ Prohibitin, ${ }^{77}$ generally a deeply raft-related protein, is present at synaptic sites and induces changes in spine morphology ${ }^{81}$ A role of prohibitin as a regulator of synaptic contacts is suggested, since it is involved in the localization of the adhesion complex proteins, cadherin and $\beta$-catenin, to the plasma membrane. ${ }^{82} \mathrm{~A}$ knockdown experiment on paralemmin- $1^{83}$ suggested a role for the protein in spine maturation and filopodia induction. A major role of NAP22 is related to synaptic vesicle functions, ${ }^{84,85}$ although postsynaptic function is unknown. GAP43 depletion and overexpression suggest a role for neurite formation and axonal sprouting. ${ }^{86,87}$

The SPM-DRMs we obtained are highly enriched with a number of raft-marker proteins (contactin-1/F3, G-protein $\beta$-subunit, voltage-dependent anion-selective channel protein, Thy-1, and cytochrome c oxidase subunit). Properties of these proteins also support a role of PSRs in synaptic plasticity. Contactin-1 is a GPI-anchored raft protein and a member of immunoglobulin-containing cell adhesion molecules (Ig-CAMs). ${ }^{8}$ Contactin-1 deficient mice are specifically impaired in paired-pulse facilitation and long-term depression (LTD), but not long-term potentiation (LTP), in CA1 pyramidal cells. Contactin-1 appears not to be related to synapse development but to synaptic plasticity, and in particular LTD maintenance. ${ }^{89}$ Localization of contactin-1 in dendrites, dendritic spine heads, and PSDs in the hippocampus ${ }^{90}$ supports its role at the synapse. Lack of Thy-1, an Ig-CAM, ${ }^{89}$ blocks LTP. $^{91}$
Caveolins have been considered to be present only in caveolae and not in noncaveolar membrane rafts. Recently, however, extracaveolae localization and function became a point of interest. In particular, neurons, as well as leukocytes, express caveolins in spite of the absence of caveolae. ${ }^{92,93}$ Furthermore, caveolin-1 is localized in type I PSDs of mature synapses, which lack caveolae. ${ }^{34}$ Therefore, the notion that caveolins are localized only in caveolae rafts (flask-shaped rafts) but not in noncaveolar planner rafts needs to be revisited. Finally, caveolin-knockout mice show neurological abnormalities ${ }^{94}$ and impairment of spatial memory. ${ }^{95}$ Conversely, overexpression of caveolin-1 in hippocampal neurons in culture increases synapse density, synapse protein expression, and neuronal arborization..$^{96}$ Thus, it is strongly suggested that caveolin functions not only in caveolae but also outside the caveolae. Together, roles of these preferential raft-resident proteins support involvement of PSRs in synaptic functions and plasticity.

\section{PSRs in synaptogenesis}

Many synaptogenic events, such as accumulating and clustering receptors and scaffolding proteins to specific contact sites, may be greatly facilitated by dynamic changes of membrane rafts in addition to local protein-protein interactions. ${ }^{97}$ Roles of membrane rafts in synaptogenesis may, at least partly, be due to the presence of many synaptic cell adhesion molecules. ${ }^{28,30}$ Some of these cell adhesion molecules work as synapse organizers. ${ }^{98,99}$ Specific cell adhesion molecules accumulate at pre- and postsynaptic sites and trigger synapse formation. ${ }^{88,98-102}$ The importance of cell adhesion molecules in synaptogenesis is also evident, since gene abnormality in synaptic cell adhesion molecules and closely related proteins cause impairments in synapse and/or spine number and morphology. ${ }^{99,103}$ Cholesterol is also required for synaptogenesis, in addition to maturation and maintenance of synapse. ${ }^{48,59-62}$ Synaptogenesis in vitro can be promoted by glia-derived cholesterol, which suggests that cholesterol-rich membrane rafts are involved in synapse maturation and stability. ${ }^{43,61,104}$ Involvement of membrane rafts in central nervous system synaptogenesis is also suggested in a mechanism for AChR clustering, an early event of synaptogenesis of the neuromuscular junction. ${ }^{49,105,106}$ Targeting to the neuromuscular junction of AChRs and rapsyn, which is necessary for AChR clustering, appears to be mediated by membrane rafts. ${ }^{107}$ Finally, membrane rafts regulate formation of immunological synapses (ISs), ${ }^{97}$ which possibly share common structural and functional properties and mechanisms with neuronal synapses as cell-cell contact sites (see following section). 
Together, PSRs may play an important role not only in function and plasticity of mature synapses but also in synaptogenesis during development.

\section{PSRs in postsynaptic signaling}

PSDs are a major site of signal processing at the synapse. Although the PSD contains a number of signaling molecules, most signal-processing events at the postsynaptic sites may require postsynaptic membranes similar to the processing of extracellular signals in nonneuronal cells, ${ }^{46,108}$ where signaling molecules are recruited to temporally formed membrane raft platforms. Raft aggregation works as a switch, which turns the signaling reactions on and off. Recruitment of intracellular signaling molecules to membrane raft domains, which contain membrane proteins activated by extracellular signals, forms signalosomes, but signaling reactions last only temporally following the disintegration of raft aggregations and signalosomes. Thus, membrane rafts regulate the lateral movement of membrane proteins and intracellular signaling reactions. ${ }^{108}$ Other factors that may affect the lateral movement of membrane proteins are "fences" and "pickets," as well as protein-protein interactions. ${ }^{97,108,109}$ Fences are membrane skeletal networks, mainly actin meshwork, immediately underneath the plasma membrane, ${ }^{110}$ and pickets are transmembrane proteins positioning at fixed sites on the membrane by cross-linking to membrane skeletal meshwork. Movement of membrane proteins, which tend to move freely in the membrane, is hindered by these physical obstacles and protein-protein interactions. Models of dynamics of membrane proteins in nonsynaptic areas are illustrated in Figure 5A. Figure 5B shows a simplified application of fence-and-picket model to the postsynaptic membrane at the synaptic region, where fences and pickets are denser than nonsynaptic areas because PSDs are more densely packed with proteins, and because membrane raft domains are highly heterogeneous and abundant due to enrichment of cholesterol ${ }^{33}$ and gangliosides. ${ }^{65}$ Under these conditions at the postsynaptic region, cellular signaling may be greatly facilitated during synaptic activation. Coalescence of PSRs may occur more easily and frequently, and coalesced PSRs tend to last longer due to stabilization by interactions with numerous PSD proteins. This may cause rapid, frequent, multiple, and widespread signaling and facilitates signaling at postsynaptic sites. Therefore, it is highly plausible

\section{A Non-synaptic membrane}

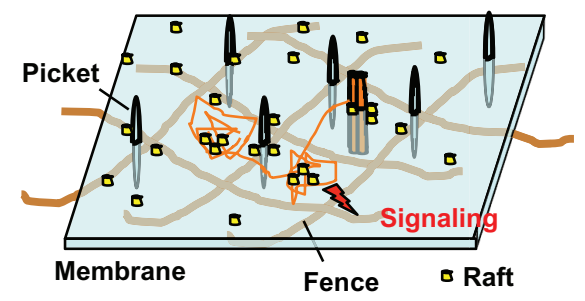

B Postsynaptic side of synapse

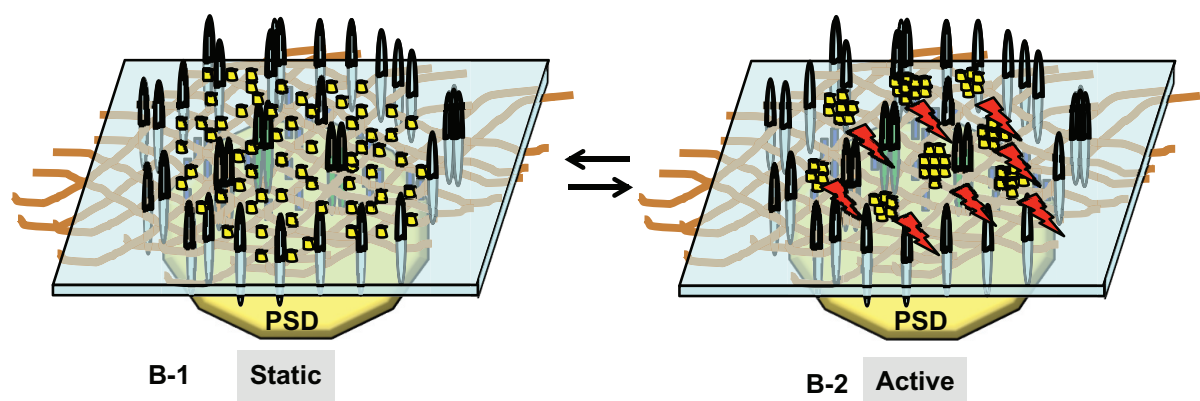

Figure 5 (A and B) Model for localization and dynamics of PSRs. (A) "Fence-and-picket" membrane model for nonneuronal cells. Line drawing (orange) indicates lateral movement of a single membrane protein. (B) A modified fence-and-picket model for postsynaptic membrane. Membrane rafts localized away from postsynaptic membranes and associated with intracellular vesicles are not shown for simplicity. B-I: Static condition. Fences are part of PSD structure, and pickets are transmembrane proteins linked to PSD cytoskeletons. A number of small membrane raft domains are dispersed across the postsynaptic membrane (yellow cylinders). B-2: Activated condition. Membrane raft domains in the synaptic region of postsynaptic membrane become aggregated.

Notes: Modified from Kusumi A, Ike H, Nakada C, Murase K, Fujiwara T. Single-molecule tracking of membrane molecules: plasma membrane compartmentalization and dynamic assembly of raft-philic signaling molecules. Semin Immunol. 2005; 17:3-21, Copyright 2005, with permission from Elsevier. ${ }^{109}$

Abbreviations: PSD, postsynaptic density; PSR, postsynaptic membrane raft. 
that PSRs are necessary and indispensable for postsynaptic signaling.

\section{Involvement of PSRs in PSD thickening, one type of synaptic plasticity}

We reported the phenomenon of PSD thickening, which was caused by translocation of CaMKII into PSDs. ${ }^{18}$ It was later shown that PSD thickening occurs not only under pathological conditions such as ischemia, as we suggested initially, but also occurs under near physiological conditions upon synaptic activation or potentiation under high $\mathrm{K}^{+}$stimulation, following glutamate/glycine stimulation, and after chemically induced LTP. ${ }^{111,112}$ In contrast to the irreversible nature of ischemia-related PSD thickening, PSD thickening following synapse stimulation is reversible.

Our recent study suggests that PSD thickening is related to membrane rafts. ${ }^{27}$ PSD thickening appears to be caused by translocation of CaMKII molecules into the PSD and accumulation of clustered CaMKII in the PSD. The CaMKII clustering can be induced in cultured neurons by glutamate/ glycine and in CaMKII $\alpha$-transfected human embryonic kidney (HEK) 293 cells by ionomycin. ${ }^{113}$ Using these protocols, we found that 1) CaMKII, either in clustered or nonclustered form, is associated with membrane rafts, 2) membrane rafts become stabilized when CaMKII are clustered, being resistant to TX-100 solubilization subsequent to cholesterol extraction with methyl- $\beta$-cyclodextrin, and 3) CaMKII clustering traps PSD-95, which is also localized to membrane rafts independently of CaMKII, into CaMKII clusters in stabilized membrane rafts. Figure 6 summarizes the experiment showing this PSD-95 trapping by CaMKII cluster-containing membrane rafts. ${ }^{27}$

It is well established that CaMKII binds a number of PSD proteins $^{114,115}$ and that CaMKII may serve as a seed molecule for PSD protein assembly. ${ }^{113}$ Trapping of PSD proteins into CaMKII cluster-containing membrane rafts, which possibly leads to PSD thickening, might be a mechanism for PSD enlargement and strengthening. CaMKII-containing membrane rafts can trap PSD proteins localized in the rafts and/or proteins with affinity to membrane rafts, even if they do not directly interact with CaMKII. The trapping of PSD-95 is a typical example. Many other PSD proteins with the potential to associate with membrane rafts can be trapped into CaMKII cluster-associated PSDs in a similar manner. Thus, PSRs may be involved in this type of synaptic
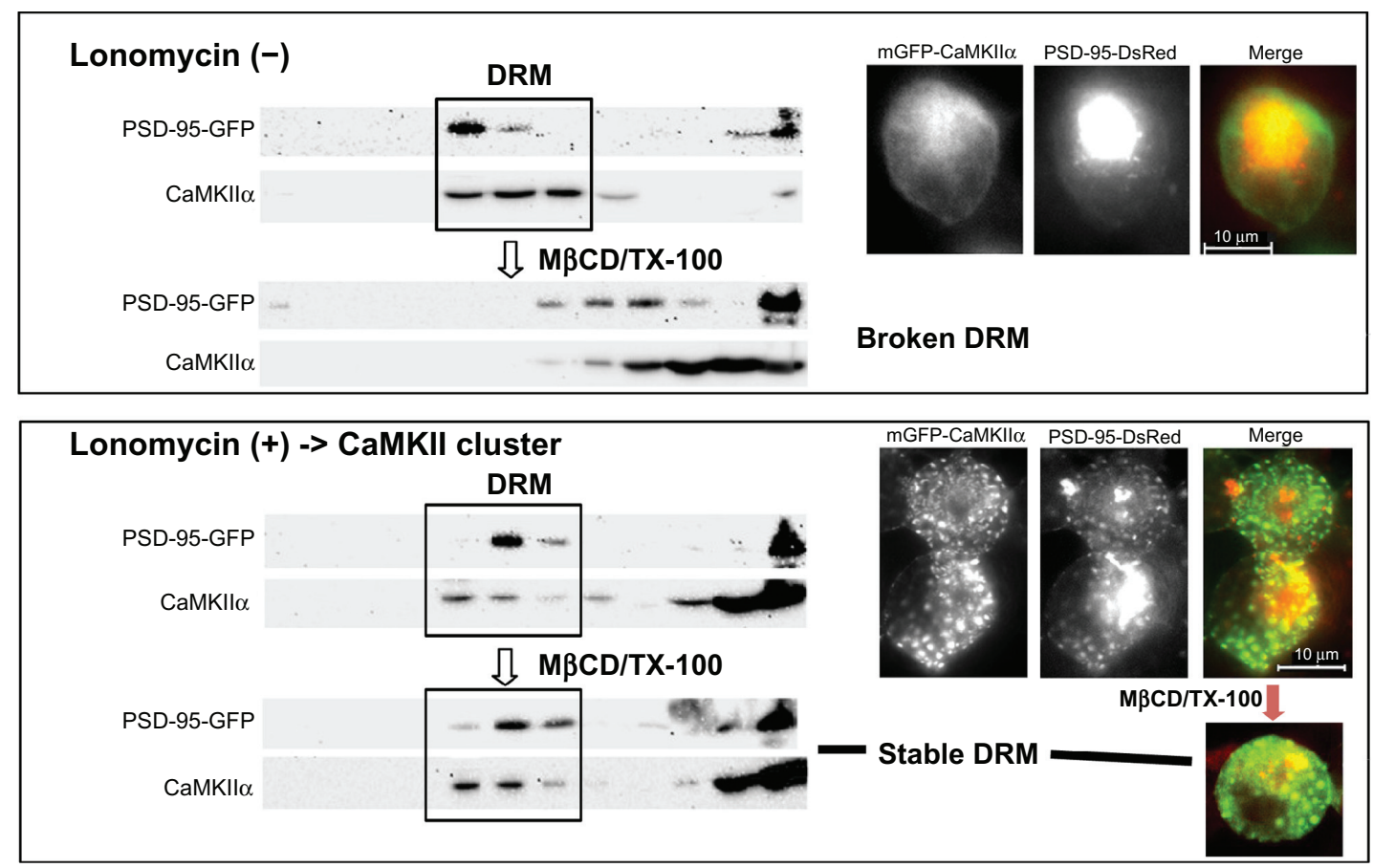

Figure 6 Trapping of PSD-95 by CaMKII cluster-containing membrane rafts. GFP-CaMKIll $\alpha$ and PSD-DsRed were coexpressed in human embryonic kidney cells. They were localized to DRMs, but did not colocalize when the cells were untreated with ionomycin. However, after inducing CaMKII clustering by ionomycin, clusters containing both CaMKII and PSD-95 appeared, and their distribution in the DRMs became resistant to MBCD/TX-100. Copyright @ 2007, John Wiley and Sons. Suzuki T, Du F, Tian QB, Zhang J, Endo S. Ca ${ }^{2+} / c a l m o d u l i n-$ dependent protein kinase ll $\alpha$ clusters are associated with stable lipid rafts and their formation traps PSD-95. J Neurochem. 2008;104:596-610.27

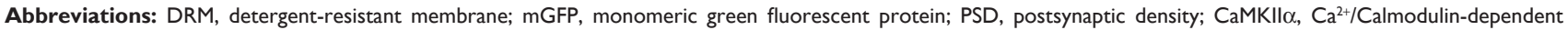
kinase Il $\alpha$ subunit; $M \beta C D$, methyl- $\beta$-cyclodextrin. 
plasticity. This is an example of functional interplay between PSDs and PSRs.

\section{Roles of membrane rafts in nonsynaptic cell-cell contact sites}

Synapses in the brain are specialized forms of cell-cell contact sites. Various types of cell-cell contact sites may share common structural and functional properties and mechanisms, although they are specifically differentiated structures and thus hold their own characteristics. Therefore, one can deduce fundamental properties of synapses, such as functions of synaptic rafts, from other well-investigated and -characterized types of cell-cell contact sites. ISs and tight junctions are such examples. ISs are formed between $\mathrm{T}$ cells and other immunological cells, in particular antigenpresenting cells (APC), ${ }^{116,117}$ are constituted with different proteins, and lack "PSD-like" large protein complexes immediately underneath the plasma membrane. However, ISs and neuronal synapses share common structural and functional properties. Both structures are specialized devices developed for efficient cell-cell communication and signaling, to which cell adhesion molecules, ligand proteins, and receptor proteins are mobilized. Both are dynamic structures, because ISs are formed only transiently and neuronal

\section{A Possible roles of PSRs}

-Synaptogenesis, PSD construction

- Maintenance of PSD structure

as membrane-cytoskeleton anchor site

-Signaling platform

-Receptor movement (eg, AMPAR)

by endocytosis, exocytosis, lateral movement

- Supply of membrane for spine enlargement

by exocytosis

\section{B}

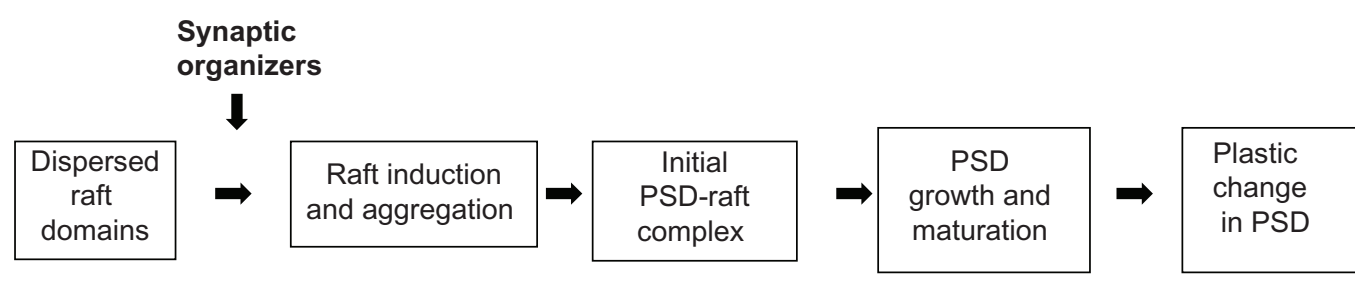

$\begin{array}{lll}\begin{array}{l}\text { Clustering } \\ \text { of receptors, } \\ \text { cell adhesion } \\ \text { molecules }\end{array} & \begin{array}{l}\text { Assembly } \\ \text { of PSD-core } \\ \text { components }\end{array} & \begin{array}{l}\text { Addition of scaffold/adaptor } \\ \text { proteins }\end{array} \\ & \begin{array}{l}\text { Addition of signaling molecules } \\ \text { Reorganization of PSR and PSD }\end{array} \\ & \text { PSD thickening } \\ & \begin{array}{l}\text { Morphological changes } \\ \text { in spine }\end{array}\end{array}$

Figure 7 (A and B) Possible roles of membrane rafts at postsynaptic sites. (A) Possible roles of PSRs. (B) Possible raft involvement in PSD construction, maintenance, and reorganization. PSDs and PSRs may work together at all developmental stages of synapses.

Abbreviations: PSD, postsynaptic density; PSR, postsynaptic membrane raft; AMPAR, $\alpha$-amino-3-hydroxy-5-methyl-4-isoxazolepropionic acid receptor. 
synapses also change their size, morphology, and number frequently in response to activity. Tight junctions are also called epithelium synapses, ${ }^{118}$ because they are enriched in synaptic and signaling proteins, and the cytoplasmic side underlying tight junctions contains multimolecular protein complexes similar to PSDs of neuronal synapses. ${ }^{119}$

Raft involvement in postsynaptic activities is supported by the knowledge gained for membrane rafts of ISs and tight junctions. It has been clearly shown that IS membranes contain membrane raft domains, which were visualized by fluorescein isothiocyanate-labeled cholera toxin B subunit, a $\mathrm{G}_{\mathrm{M} 1}$ ganglioside probe. ${ }^{120}$ Membrane rafts are already a recognized component in molecular architecture models of ISs. ${ }^{97,121}$ Involvement of membrane raft activities is indicated in the formation, maintenance, and functions of ISs. It is suggested that membrane rafts in future IS regions are stabilized and then aggregated in a receptor-mediated manner at the early stage of IS formation, and this may be necessary for mobilization of IS components to IS and intracellular T-cell signaling. ${ }^{97}$ Tight junctions are also associated with membrane raft domains and raft-associable proteins. ${ }^{122,123}$ In addition, cell adhesion points and cell-cell contact regions are particularly enriched in membrane rafts, ${ }^{124}$ which suggests that these sites require activities of membrane rafts. Thus, it is likely that association and coordination of synapses and synapse-like structures with membrane rafts are common mechanisms for sustained and large-scale $(\sim \mathrm{a}$ few $\mu \mathrm{m})$ cellcell signaling.

\section{Conclusion}

PSRs are essential components of postsynaptic signaling machinery connected to PSDs, providing membrane anchor sites for PSD cytoskeletons/scaffolds, as well as signaling platforms and sites for membrane fusion and vesicular trafficking. As a result, PSRs and PSD-PSR interplay may play important yet underappreciated roles in synaptogenesis, synapse maturation and maintenance, and synaptic function and plasticity. Possible roles of membrane rafts at postsynaptic sites are summarized in Figure 7A. Membrane rafts are distributed in both pre- and postsynaptic sites in all components of a neuron, including axons, dendrites, and somas, and in both immature and mature neurons, suggesting widespread functions for them in the central nervous system.

Based on tight and dynamic physical interactions between PSDs and PSRs and their associated proteins, it is likely postsynaptic activities require both PSDs and PSRs. We propose that PSDs and PSRs work together at all developmental stages of the synapse. Figure 7B depicts our working hypothesis on PSD-PSR coupling that may be involved in molecular processes of synaptogenesis, synaptic growth, synaptic stability, and plasticity. Membrane raft domains in dispersed states at the sites of future synapses may assemble into platforms where receptors and cell adhesion molecules assemble and form clusters. PSD core components containing certain scaffolding/adaptor proteins and cytoskeletal proteins then begin to accumulate and assemble, and initial PSD- and PSR-containing structures may be formed at these sites. Scaffolding/adaptor proteins and molecules necessary for PSD functions, such as signaling molecules, are added and allocated strategically to proper sites in the PSD- and PSR-containing structures, and these structures develop as synapses mature and stabilize.

PSRs have not been included in current models of postsynaptic structures and functions, and will certainly need to be added in the future. Many more studies are required to provide detailed information on underlying mechanisms, dynamic regulation, and physiological significance of PSD PSR interactions. Investigations of PSRs and PSDs are essential to understand synaptic transmission and its regulation and plasticity under both physiological and pathological conditions. Furthermore, augmentation of synaptic raft function may lead to strengthening and repair of synaptic function. ${ }^{96,125}$ The knowledge gained will be important for developing therapeutical approaches to neurological and psychiatric diseases caused by synapse dysfunctions.

\section{Disclosure}

The authors report no conflicts of interest in this work.

\section{References}

1. Simons K, Ikonen E. Functional rafts in cell membranes. Nature. 1997;387:569-572.

2. Pike LJ. Rafts defined: a report on the Keystone Symposium on Lipid Rafts and Cell Function. J Lipid Res. 2006;47:1597-1598.

3. Ziff EB. Enlightening the postsynaptic density. Neuron. 1997;19: 1163-1174.

4. Sheng M, Hoogenraad CC. The postsynaptic architecture of excitatory synapses: a more quantitative view. Annu Rev Biochem. 2007;76: 823-847.

5. Boeckers TM. The postsynaptic density. Cell Tissue Res. 2006;326: 409-422.

6. Palay SL. The morphology of synapses in the central nervous system Exp Cell Res. 1958;14:275-293.

7. Kennedy MB. Signal-processing machines at the postsynaptic density. Science. 2000;290:750-754.

8. Baron MK, Boeckers TM, Vaida B, et al. An architectural framework that may lie at the core of the postsynaptic density. Science. 2006;311: $531-535$. 
9. Suzuki T. Isolation of synapse subdomains by subcellular fractionation using sucrose density gradient centrifugation. In: Li KW, editor. Neuroproteomics (Neuromethods). New York: Humana Press; 2011: 47-61.

10. Satoh K, Takeuchi M, Oda Y, et al. Identification of activity-regulated proteins in the postsynaptic density fraction. Genes Cells. 2002;7: 187-197.

11. Jordan BA, Fernholz BD, Boussac M, et al. Identification and verification of novel rodent postsynaptic density proteins. Mol Cell Proteomics. 2004;3:857-871.

12. Li KW, Hornshaw MP, Van Der Schors RC, et al. Proteomics analysis of rat brain postsynaptic density. Implications of the diverse protein functional groups for the integration of synaptic physiology. $J$ Biol Chem. 2004;279:987-1002.

13. Peng J, Kim MJ, Cheng D, Duong DM, Gygi SP, Sheng M. Semiquantitative proteomic analysis of rat forebrain postsynaptic density fractions by mass spectrometry. J Biol Chem. 2004;279:21003-21011.

14. Yoshimura Y, Yamauchi Y, Shinkawa T, et al. Molecular constituents of the postsynaptic density fraction revealed by proteomic analysis using multidimensional liquid chromatography-tandem mass spectrometry. J Neurochem. 2004;88:759-768.

15. Cheng D, Hoogenraad CC, Rush J, et al. Relative and absolute quantification of postsynaptic density proteome isolated from rat forebrain and cerebellum. Mol Cell Proteomics. 2006;5:1158-1170.

16. Suzuki T, Tian QB, Kuromitsu J, Kawai T, Endo S. Characterization of mRNA species that are associated with postsynaptic density fraction by gene chip microarray analysis. Neurosci Res. 2007;57:61-85.

17. Sugiyama Y, Kawabata I, Sobue K, Okabe S. Determination of absolute protein numbers in single synapses by a GFP-based calibration technique. Nat Methods. 2005;2:677-684.

18. Suzuki T, Okumura-Noji K, Tanaka R, Tada T. Rapid translocation of cytosolic $\mathrm{Ca} 2+$ /calmodulin-dependent protein kinase II into postsynaptic density after decapitation. J Neurochem. 1994;63:1529-1537.

19. Cheng HH, Huang ZH, Lin WH, Chow WY, Chang YC. Cold-induced exodus of postsynaptic proteins from dendritic spines. J Neurosci Res. 2009;87:460-469.

20. Chen X, Vinade L, Leapman RD, et al. Mass of the postsynaptic density and enumeration of three key molecules. Proc Natl Acad Sci US A. 2005;102:11551-11556.

21. Feng W, Zhang M. Organization and dynamics of PDZ-domainrelated supramodules in the postsynaptic density. Nat Rev Neurosci. 2009;10:87-99.

22. Kim E, Sheng M. PDZ domain proteins of synapses. Nat Rev Neurosci. 2004;5:771-781.

23. Yen YH, Chuang CF, Chang CW, Chang YC. A study of the spatial protein organization of the postsynaptic density isolated from porcine cerebral cortex and cerebellum. Mol Cell Proteomics. 2011;10: M110.007138.

24. Chang CW, Peng SC, Cheng WY, et al. Studying the protein-protein interactions in the postsynaptic density by means of immunoabsorption and chemical crosslinking. Proteomics Clin Appl. 2007;1:1499-1512.

25. Suzuki T. Lipid rafts at postsynaptic sites: distribution, function and linkage to postsynaptic density. Neurosci Res. 2002;44:1-9.

26. Suzuki T, Ito J, Takagi H, Saitoh F, Nawa H, Shimizu H. Biochemical evidence for localization of AMPA-type glutamate receptor subunits in the dendritic raft. Brain Res Mol Brain Res. 2001;89:20-28.

27. Suzuki T, Du F, Tian QB, Zhang J, Endo S. $\mathrm{Ca}^{2+} /$ calmodulin-dependent protein kinase II $\alpha$ clusters are associated with stable lipid rafts and their formation traps PSD-95. J Neurochem. 2008;104:596-610.

28. Suzuki T, Zhang J, Miyazawa S, Liu Q, Farzan MR, Yao WD. Association of membrane rafts and postsynaptic density: proteomics, biochemical, and ultrastructural analyses. J Neurochem. 2011;119:64-77.

29. Williamson R, Thompson AJ, Abu M, et al. Isolation of detergent resistant microdomains from cultured neurons: detergent dependent alterations in protein composition. BMC Neurosci. 2010;11:120.

30. Liu Q, Yao WD, Suzuki T. Specific interaction of postsynaptic densities with membrane rafts isolated from synaptic plasma membranes. J Neurogenet. 2013;27:43-58.
31. Garner AE, Smith DA, Hooper NM. Visualization of detergent solubilization of membranes: implications for the isolation of rafts. Biophys J. 2008;94:1326-1340.

32. Anderson RG, Jacobson K. A role for lipid shells in targeting proteins to caveolae, rafts, and other lipid domains. Science. 2002;296: 1821-1825.

33. Korade Z, Kenworthy AK. Lipid rafts, cholesterol, and the brain. Neuropharmacology. 2008;55:1265-1273.

34. Petralia RS, Wang YX, Wenthold RJ. Internalization at glutamatergic synapses during development. Eur J Neurosci. 2003;18:3207-3217.

35. Kachidian P, Vuillet J, Bartoli M, Castets F, Nieoullon A, Kerkerian-Le Goff L. Relationships between striatin-containing neurons and cortical or thalamic afferent fibres in the rat striatum. An ultrastructural study by dual labelling. Neuroscience. 1998;85:111-122.

36. Castets F, Bartoli M, Barnier JV, et al. A novel calmodulin-binding protein, belonging to the WD-repeat family, is localized in dendrites of a subset of CNS neurons. J Cell Biol. 1996;134:1051-1062.

37. Benoist M, Baude A, Tasmadjian A, Dargent B, Kessler JP, Castets F. Distribution of zinedin in the rat brain. J Neurochem. 2008;106: 969-977.

38. Kutzleb C, Sanders G, Yamamoto R, et al. Paralemmin, a prenylpalmitoyl-anchored phosphoprotein abundant in neurons and implicated in plasma membrane dynamics and cell process formation. J Cell Biol. 1998;143:795-813.

39. Iino S, Maekawa S. Immunohistochemical demonstration of a neuronal calmodulin-binding protein, NAP-22, in the rat spinal cord. Brain Res. 1999;834:66-73.

40. Li X, Serwanski DR, Miralles CP, Bahr BA, De Blas AL. Two pools of Triton $\mathrm{X}$-100-insoluble GABA(A) receptors are present in the brain, one associated to lipid rafts and another one to the post-synaptic GABAergic complex. J Neurochem. 2007;102:1329-1345.

41. Allen JA, Halverson-Tamboli RA, Rasenick MM. Lipid raft microdomains and neurotransmitter signalling. Nat Rev Neurosci. 2007;8:128-140.

42. Becher A, White JH, McIlhinney RA. The gamma-aminobutyric acid receptor $\mathrm{B}$, but not the metabotropic glutamate receptor type-1, associates with lipid rafts in the rat cerebellum. J Neurochem. 2001;79: 787-795.

43. Brusés JL, Chauvet N, Rutishauser U. Membrane lipid rafts are necessary for the maintenance of the (alpha)7 nicotinic acetylcholine receptor in somatic spines of ciliary neurons. $J$ Neurosci. 2001;21: 504-512.

44. Oldfield S, Hancock J, Mason A, et al. Receptor-mediated suppression of potassium currents requires colocalization within lipid rafts. $\mathrm{Mol}$ Pharmacol. 2009;76:1279-1289.

45. Voulalas PJ, Schetz J, Undieh AS. Differential subcellular distribution of rat brain dopamine receptors and subtype-specific redistribution induced by cocaine. Mol Cell Neurosci. 2011;46:645-654.

46. Sebastião AM, Colino-Oliveira M, Assaife-Lopes N, Dias RB, Ribeiro JA. Lipid rafts, synaptic transmission and plasticity: impact in age-related neurodegenerative diseases. Neuropharmacology. 2013;64:97-107.

47. Fritschy JM, Harvey RJ, Schwarz G. Gephyrin: where do we stand, where do we go? Trends Neurosci. 2008;31:257-264.

48. Hering H, Lin CC, Sheng M. Lipid rafts in the maintenance of synapses, dendritic spines, and surface AMPA receptor stability. $J$ Neurosci. 2003;23:3262-3271.

49. Zhu D, Xiong WC, Mei L. Lipid rafts serve as a signaling platform for nicotinic acetylcholine receptor clustering. J Neurosci. 2006;26: $4841-4851$.

50. Kang R, Wan J, Arstikaitis P, et al. Neural palmitoyl-proteomics reveals dynamic synaptic palmitoylation. Nature. 2008;456:904-909.

51. el-Husseini Ael D, Bredt DS. Protein palmitoylation: a regulator of neuronal development and function. Nat Rev Neurosci. 2002;3:791-802.

52. Lucero HA, Robbins PW. Lipid rafts-protein association and the regulation of protein activity. Arch Biochem Biophys. 2004;426: 208-224. 
53. Levental I, Grzybek M, Simons K. Greasing their way: lipid modifications determine protein association with membrane rafts. Biochemistry. 2010;49:6305-6316.

54. Suh BC, Hille B. Regulation of ion channels by phosphatidylinositol 4,5-bisphosphate. Curr Opin Neurobiol. 2005;15:370-378.

55. McLaughlin S, Wang J, Gambhir A, Murray D. PIP 2 and proteins: interactions, organization, and information flow. Annu Rev Biophys Biomol Struct. 2002;31:151-175.

56. Du F, Saitoh F, Tian QB, Miyazawa S, Endo S, Suzuki T. Mechanisms for association of $\mathrm{Ca} 2+$ /calmodulin-dependent protein kinase II with lipid rafts. Biochem Biophys Res Commun. 2006;347:814-820.

57. Besshoh S, Bawa D, Teves L, Wallace MC, Gurd JW. Increased phosphorylation and redistribution of NMDA receptors between synaptic lipid rafts and post-synaptic densities following transient global ischemia in the rat brain. J Neurochem. 2005;93:186-194.

58. Delint-Ramírez I, Salcedo-Tello P, Bermudez-Rattoni F. Spatial memory formation induces recruitment of NMDA receptor and PSD-95 to synaptic lipid rafts. J Neurochem. 2008;106:1658-1668.

59. Fan QW, Yu W, Gong JS, et al. Cholesterol-dependent modulation of dendrite outgrowth and microtubule stability in cultured neurons J Neurochem. 2002;80:178-190.

60. Göritz C, Mauch DH, Nägler K, Pfrieger FW. Role of glia-derived cholesterol in synaptogenesis: new revelations in the synapse-glia affair J Physiol Paris. 2002;96:257-263.

61. Pfrieger FW. Outsourcing in the brain: do neurons depend on cholesterol delivery by astrocytes? Bioessays. 2003;25:72-78.

62. Slezak M, Pfrieger FW. New roles for astrocytes: regulation of CNS synaptogenesis. Trends Neurosci. 2003;26:531-535.

63. Koudinov AR, Koudinova NV. Essential role for cholesterol in synaptic plasticity and neuronal degeneration. FASEB J. 2001;15:1858-1860.

64. Frank C, Rufini S, Tancredi V, Forcina R, Grossi D, D’Arcangelo G. Cholesterol depletion inhibits synaptic transmission and synaptic plasticity in rat hippocampus. Exp Neurol. 2008;212:407-414.

65. Mocchetti I. Exogenous gangliosides, neuronal plasticity and repair, and the neurotrophins. Cell Mol Life Sci. 2005;62:2283-2294.

66. Lopez PH, Schnaar RL. Gangliosides in cell recognition and membrane protein regulation. Curr Opin Struct Biol. 2009;19:549-557.

67. Regina Todeschini A, Hakomori SI. Functional role of glycosphingolipids and gangliosides in control of cell adhesion, motility, and growth, through glycosynaptic microdomains. Biochim Biophys Acta. 2008; 1780:421-433.

68. Prinetti A, Iwabuchi K, Hakomori S. Glycosphingolipid-enriched signaling domain in mouse neuroblastoma Neuro2a cells. Mechanism of ganglioside-dependent neuritogenesis. J Biol Chem. 1999;274: 20916-20924.

69. Chichili GR, Rodgers W. Cytoskeleton-membrane interactions in membrane raft structure. Cell Mol Life Sci. 2009;66:2319-2328.

70. Paladino S, Sarnataro D, Pillich R, Tivodar S, Nitsch L, Zurzolo C. Protein oligomerization modulates raft partitioning and apical sorting of GPI-anchored proteins. J Cell Biol. 2004;167:699-709.

71. Golub T, Wacha S, Caroni P. Spatial and temporal control of signaling through lipid rafts. Curr Opin Neurobiol. 2004;14:542-550.

72. Hou Q, Huang Y, Amato S, Snyder SH, Huganir RL, Man HY. Regulation of AMPA receptor localization in lipid rafts. Mol Cell Neurosci. 2008;38:213-223.

73. Pediconi MF, Gallegos CE, De Los Santos EB, Barrantes FJ. Metabolic cholesterol depletion hinders cell-surface trafficking of the nicotinic acetylcholine receptor. Neuroscience. 2004;128:239-249.

74. Swanwick CC, Shapiro ME, Vicini S, Wenthold RJ. Flotillin-1 promotes formation of glutamatergic synapses in hippocampal neurons. Dev Neurobiol. 2010;70:875-883.

75. Swanwick CC, Shapiro ME, Vicini S, Wenthold RJ. Flotillin-1 mediates neurite branching induced by synaptic adhesion-like molecule 4 in hippocampal neurons. Mol Cell Neurosci. 2010;45:213-225.

76. Bodrikov V, Solis GP, Stuermer CA. Prion protein promotes growth cone development through reggie/flotillin-dependent $\mathrm{N}$-cadherin trafficking. J Neurosci. 2011;31:18013-18025.
77. Browman DT, Hoegg MB, Robbins SM. The SPFH domain-containing proteins: more than lipid raft markers. Trends Cell Biol. 2007;17: 394-402.

78. Bartoli M, Ternaux JP, Forni C, et al. Down-regulation of striatin, a neuronal calmodulin-binding protein, impairs rat locomotor activity. J Neurobiol. 1999;40:234-243.

79. Haeberle AM, Castets F, Bombarde G, Baillat G, Bailly Y. Immunogold localization of phocein in dendritic spines. J Comp Neurol. 2006;495: 336-350.

80. Benoist M, Gaillard S, Castets F. The striatin family: a new signaling platform in dendritic spines. J Physiol Paris. 2006;99:146-153.

81. Smalla KH, Mikhaylova M, Sahin J, et al. A comparison of the synaptic proteome in human chronic schizophrenia and rat ketamine psychosis suggest that prohibitin is involved in the synaptic pathology of schizophrenia. Mol Psychiatry. 2008;13:878-896.

82. Rajalingam K, Wunder C, Brinkmann V, et al. Prohibitin is required for Ras-induced Raf-MEK-ERK activation and epithelial cell migration. Nat Cell Biol. 2005;7:837-843.

83. Arstikaitis P, Gauthier-Campbell C, Carolina Gutierrez Herrera R, et al. Paralemmin-1, a modulator of filopodia induction is required for spine maturation. Mol Biol Cell. 2008;19:2026-2038.

84. Yamamoto Y, Sokawa Y, Maekawa S. Biochemical evidence for the presence of NAP-22, a novel acidic calmodulin binding protein, in the synaptic vesicles of rat brain. Neurosci Lett. 1997;224:127-130.

85. Maekawa S, Kobayashi Y, Odagaki S, et al. Interaction of NAP-22 with brain glutamic acid decarboxylase (GAD). Neurosci Lett. 2013;537: 50-54.

86. Allegra Mascaro AL, Cesare P, Sacconi L, et al. In vivo single branch axotomy induces GAP-43-dependent sprouting and synaptic remodeling in cerebellar cortex. Proc Natl Acad Sci U S A. 2013;110:10824-10829.

87. Aigner L, Arber S, Kapfhammer JP, et al. Overexpression of the neural growth-associated protein GAP-43 induces nerve sprouting in the adult nervous system of transgenic mice. Cell. 1995;83:269-278.

88. Bukalo O, Dityatev A. Synaptic cell adhesion molecules. Adv Exp Med Biol. 2012;970:97-128.

89. Dityatev A, Bukalo O, Schachner M. Modulation of synaptic transmission and plasticity by cell adhesion and repulsion molecules. Neuron Glia Biol. 2008;4:197-209.

90. Murai KK, Misner D, Ranscht B. Contactin supports synaptic plasticity associated with hippocampal long-term depression but not potentiation. Curr Biol. 2002;12:181-190.

91. Nosten-Bertrand M, Errington ML, Murphy KP, et al. Normal spatial learning despite regional inhibition of LTP in mice lacking Thy-1. Nature. 1996;379:826-829.

92. Head BP, Insel PA. Do caveolins regulate cells by actions outside of caveolae? Trends Cell Biol. 2007;17:51-57.

93. Head BP, Patel HH, Insel PA. Interaction of membrane/lipid rafts with the cytoskeleton: impact on signaling and function: membrane/lipid rafts, mediators of cytoskeletal arrangement and cell signaling. Biochim Biophys Acta. Epub 2013 Jul 27.

94. Trushina E, Du Charme J, Parisi J, McMurray CT. Neurological abnormalities in caveolin-1 knock out mice. Behav Brain Res. 2006;172: 24-32.

95. Gioiosa L, Raggi C, Ricceri L, et al. Altered emotionality, spatial memory and cholinergic function in caveolin-1 knock-out mice. Behav Brain Res. 2008;188:255-262.

96. Head BP, Hu Y, Finley JC, et al. Neuron-targeted caveolin-1 protein enhances signaling and promotes arborization of primary neurons. J Biol Chem. 2011;286:33310-33321.

97. Zeyda M, Stulnig TM. Lipid Rafts and Co: An integrated model of membrane organization in T cell activation. Prog Lipid Res. 2006; 45(3):187-202.

98. Siddiqui TJ, Craig AM. Synaptic organizing complexes. Curr Opin Neurobiol. 2011;21:132-143.

99. Fox MA, Umemori H. Seeking long-term relationship: axon and target communicate to organize synaptic differentiation. J Neurochem. 2006;97:1215-1231. 
100. Washbourne P, Dityatev A, Scheiffele P, et al. Cell adhesion molecules in synapse formation. $J$ Neurosci. 2004;24:9244-9249.

101. Brose N. Synaptogenic proteins and synaptic organizers: "many hands make light work." Neuron. 2009;61:650-652.

102. Krueger DD, Tuffy LP, Papadopoulos T, Brose N. The role of neurexins and neuroligins in the formation, maturation, and function of vertebrate synapses. Curr Opin Neurobiol. 2012;22:412-422.

103. Dalva MB, McClelland AC, Kayser MS. Cell adhesion molecules: signalling functions at the synapse. Nat Rev Neurosci. 2007;8:206-220.

104. Mauch DH, Nägler K, Schumacher S, et al. CNS synaptogenesis promoted by glia-derived cholesterol. Science. 2001;294:1354-1357.

105. Stetzkowski-Marden F, Recouvreur M, Camus G, Cartaud A, Marchand S, Cartaud J. Rafts are required for acetylcholine receptor clustering. J Mol Neurosci. 2006;30:37-38.

106. Pato C, Stetzkowski-Marden F, Gaus K, Recouvreur M, Cartaud A, Cartaud J. Role of lipid rafts in agrin-elicited acetylcholine receptor clustering. Chem Biol Interact. 2008;175:64-67.

107. Marchand S, Devillers-Thiery A, Pons S, Changeux JP, Cartaud J. Rapsyn escorts the nicotinic acetylcholine receptor along the exocytic pathway via association with lipid rafts. J Neurosci. 2002;22:8891-8901.

108. Kusumi A, Suzuki K. Toward understanding the dynamics of membrane-raft-based molecular interactions. Biochim Biophys Acta. 2005;1746:234-251.

109. Kusumi A, Ike H, Nakada C, Murase K, Fujiwara T. Single-molecule tracking of membrane molecules: plasma membrane compartmentalization and dynamic assembly of raft-philic signaling molecules. Semin Immunol. 2005;17:3-21.

110. Morone N, Fujiwara T, Murase K, et al. Three-dimensional reconstruction of the membrane skeleton at the plasma membrane interface by electron tomography. J Cell Biol. 2006;174:851-862.

111. Dosemeci A, Tao-Cheng JH, Vinade L, Winters CA, Pozzo-Miller L, Reese TS. Glutamate-induced transient modification of the postsynaptic density. Proc Natl Acad Sci U S A. 2001;98:10428-10432.

112. Otmakhov N, Tao-Cheng JH, Carpenter S, et al. Persistent accumulation of calcium/calmodulin-dependent protein kinase II in dendritic spines after induction of NMDA receptor-dependent chemical longterm potentiation. $J$ Neurosci. 2004;24:9324-9331.

113. Hudmon A, Lebel E, Roy H, et al. A mechanism for Ca2+/calmodulindependent protein kinase II clustering at synaptic and nonsynaptic sites based on self-association. J Neurosci. 2005;25:6971-6983.
114. Robison AJ, Bass MA, Jiao Y, et al. Multivalent interactions of calcium/calmodulin-dependent protein kinase II with the postsynaptic density proteins NR2B, densin-180, and alpha-actinin-2.J Biol Chem . 2005;280:35329-35336.

115. Colbran RJ. Targeting of calcium/calmodulin-dependent protein kinase II. Biochem J. 2004;378:1-16.

116. Norcross MA. A synaptic basis for T-lymphocyte activation. Ann Immunol (Paris). 1984;135D:113-134.

117. Grabrucker AM, Knight MJ, Proepper C, et al. Concerted action of zinc and ProSAP/Shank in synaptogenesis and synapse maturation. EMBO J. 2011;30:569-581.

118. Tang VW. Proteomic and bioinformatic analysis of epithelial tight junction reveals an unexpected cluster of synaptic molecules. Biol Direct. 2006;1:37.

119. Guillemot L, Paschoud S, Pulimeno P, Foglia A, Citi S. The cytoplasmic plaque of tight junctions: a scaffolding and signalling center. Biochim Biophys Acta. 2008;1778:601-613.

120. Bi K, Tanaka Y, Coudronniere N, et al. Antigen-induced translocation of PKC-theta to membrane rafts is required for T cell activation. Nat Immunol. 2001;2:556-563.

121. Friedl P, den Boer AT, Gunzer M. Tuning immune responses: diversity and adaptation of the immunological synapse. Nat Rev Immunol. 2005;5:532-545

122. Lambert D, O'Neill CA, Padfield PJ. Methyl-beta-cyclodextrin increases permeability of Caco-2 cell monolayers by displacing specific claudins from cholesterol rich domains associated with tight junctions. Cell Physiol Biochem. 2007;20:495-506.

123. Nusrat A, Parkos CA, Verkade P, et al. Tight junctions are membrane microdomains. J Cell Sci. 2000;113(Pt 10):1771-1781.

124. Gaus K, Gratton E, Kable EP, et al. Visualizing lipid structure and raft domains in living cells with two-photon microscopy. Proc Natl Acad Sci U S A. 2003;100:15554-15559.

125. Head BP, Peart JN, Panneerselvam M, et al. Loss of caveolin-1 accelerates neurodegeneration and aging. PLoS One. 2010;5:e15697.

126. Burette AC, Lesperance T, Crum J, et al. Electron tomographic analysis of synaptic ultrastructure. J Comp Neurol. 2012;520:2697-2711.
Journal of Neurorestoratology

\section{Publish your work in this journal}

The Journal of Neurorestoratology is an international, peer-reviewed, open access online journal publishing original research and review articles on the subject of Neurorestoratology. To provide complete coverage of this revolutionary field the Journal of Neurorestoratology will report on relevant experimental research, technological advances, and

\section{Dovepress}

clinical achievements. The manuscript management system is completely online and includes a very quick and fair peer-review system, which is all easy to use. Visit http://www.dovepress.com/testimonials.php to read real quotes from published authors. 